\title{
Physical properties of waxy rice starch gel with Chew-Kuk (Gnaphalium polycaulon)
}

\author{
Jittimon Wongsa ${ }^{1,2}$ and Sawanit Aichayawanich ${ }^{1 *}$ \\ ${ }^{1}$ King Mongkut's University of Technology North Bangkok, Faculty of Industrial Technology and \\ Management, Department of Agricultural Engineering for Industry, Prachinburi Campus, Prachinburi, \\ Thailand \\ ${ }^{2}$ King Mongkut's University of Technology North Bangkok, Science and Technology Research \\ Institute, Food and Agro-Industry Research Center, Bangkok, Thailand
}

\begin{abstract}
This research aimed to study effects of Chew-Kuk on physical properties of waxy rice starch gel. Sensory evaluation, color and textural profiles were determining criteria used to evaluate the waxy rice starch gel with added Chew-Kuk. The experimental results show that Chew-Kuk significantly affects color and texture of the waxy rice starch gel. Upon adding Chew-Kuk, waxy rice starch gel became yellowish green. Hardness, gumminess, and chewiness values of waxy rice starch gel with Chew-Kuk were decreased when Chew-Kuk : waxy rice starch ratios increased. Moreover, liking scores tended to be higher when adding more Chew-Kuk contents. Therefore, the suitable ratio between Chew-Kuk and waxy rice starch in this research is the highest ratio (Chew-Kuk : waxy rice starch equal to $20: 100$ ).
\end{abstract}

\section{Introduction}

Chew-Kuk (Gnaphalium polycaulon) is one of annual crops that commonly cultivated in agricultural fields. The plant belongs to the genus Gnaphaliumiun which comprises of approximately 200 species worldwide [1]. Traditionally, some species in this genus are used as a medicinal herb in some countries [2]. Moreover, several species also exhibits antioxidant and antimicrobial properties. [3, 4]. In Thailand, Chew-Kuk can be found in Bangkok, Samutsakorn, Samutsongkram, and Ratchaburi Provinces during November to January cultivation period $[5,6]$. Due to its satisfying flavor, Chew-Kuk is traditionally used to make dessert, especially during Chinese New Year celebrations. The dessert known as Ka-Nom Thien [6] consisted of waxy rice starch gel as outer coat and sweet fillings. Chew-Kuk is normally added in waxy rice starch gel in order to improve Ka-Nom Thien's flavours. It is believed that Chew-Kuk can preserve or improve textural properties of the waxy rice starch gel in Ka-Nom Thien, especially after cooling or freezing. However, little is known of ChewKuk's effects on textural properties of the waxy rice starch gel.

As mentioned above, this research aimed to investigate textural properties of the waxy rice starch gel after adding Chew-Kuk. Firstly, Chemical compositions of Chew-kuk was determined before TPA analysis of the waxy rice starch gel with added Chew-Kuk was

* Corresponding author : sawanit.a@fitm.kmutnb.c.th 
measured. Furthermore, sensory evaluation score of waxy rice gel with Chew-Kuk was also evaluated.

\section{Materials and methods}

\subsection{Materials}

Dried Chew-Kuk (stem parts and flowers) was purchased from a traditional Chinese products vendor in Bangkok, Thailand. Chemical compositions of the dried Chew-Kuk were determined following AOAC [7] methods. Waxy rice starch was obtained from a local supermarket in Prachinburi province, Thailand.

\subsection{Experimental procedures}

\subsubsection{Preparation of waxy rice starch gel with Chew-Kuk}

To prepare waxy rice starch gel with Chew-Kuk, $100 \mathrm{~g}$ of dried Chew-Kuk was fragmented for $5 \mathrm{~min}$ by grinder and subsequently boiled in water for $30 \mathrm{~min}$ at $100^{\circ} \mathrm{C}$. Then, boiled Chew-Kuk was mixed with waxy rice starch at Chew-Kuk : waxy rice starch ratios of 3:100, $5: 100,10: 100,15: 100$, and 20:100. After that, $100 \mathrm{~g}$ of the mixture was added to $80 \mathrm{~g}$ of water to produce a dough of waxy rice starch with added Chew-Kuk. Consequently, the dough then was steamed for $30 \mathrm{~min}$ at $100^{\circ} \mathrm{C}$ until waxy the rice starch gel with added ChewKuk was obtained. The waxy rice starch gel without Chew-Kuk was used as a control sample.

\subsubsection{Sensory evaluation of waxy rice starch gel with Chew-Kuk}

The sensory testing of waxy rice starch gel with added Chew-Kuk was evaluated by 30 untrained panellists who were students at the Department of Agricultural Engineering for Industry, Faculty of Industrial Technology and Management, King Mongkut's University of Technology North Bangkok Prachinburi Campus. The liking scores of color, odor, texture, appearance and overall liking were evaluated using the 5-point hedonic scale testing when $1=$ dislikes extremely, $3=$ neither like nor dislike and $5=$ like extremely.

\subsubsection{Determination of color of the waxy rice starch gel with added Chew-Kuk}

MiniScan EZ 4500L Spectrophotometer (Hunter Lab, USA) was used to determine the color of waxy rice starch gel with added Chew-Kuk. The measurement was conducted at medium daylight (D65) with a $10^{\circ}$ standard observer. The results were shown as $\mathrm{L}^{*}, \mathrm{a}^{*}, \mathrm{~b}^{*}$. Where, $\mathrm{L}^{*}$ is the measure of brightness from black $(0)$ to white $(100)$, $a^{*}$ indicates the degree of redness $\left(+a^{*}\right)$ to greenness $\left(-a^{*}\right)$ and $b^{*}$ is the measure of yellowness $\left(+b^{*}\right)$ to blueness $\left(-b^{*}\right)$.

\subsubsection{Texture profile analysis of waxy rice starch gel with added Chew-Kuk}

Texture Profile Analysis (TPA) method, which is based on the imitation of mastication or chewing process, is performed with double-compression cycles. This textural properties of the waxy rice starch gel with added Chew-Kuk were determined using a texture analyzer (CT3 4500, Brookfield, USA) by placing it at the center of the machine's base. Then, hardness, cohesiveness, springiness, gumminess and chewiness were measured with the 25/1000 standard cylindrical probe. 


\subsection{Statistical analysis}

All experiments were performed in triplicate. The data were analyzed using an analysis of variance. Duncan's multiple range test was used to establish the multiple comparisons of the mean values at $95 \%$ confident level.

\section{Results and discussions}

\subsection{Chemical composition of Chew-Kuk}

Compositions of Chew-Kuk are shown in Table 1. Fiber, carbohydrate, lipid, ash, protein and moisture contents in Chew-kuk are 0.04, 83.81, 0.86, 11.84, 0.10 and 3.38\%, respectively.

Table 1. Chemical compositions of dried Chew-Kuk.

\begin{tabular}{|c|c|}
\hline Compositions & Contents (\%) \\
\hline Fiber & 0.04 \\
\hline Carbohydrate & 83.81 \\
\hline Lipid & 0.86 \\
\hline Ash & 11.84 \\
\hline Protein & 0.10 \\
\hline Moisture & 3.38 \\
\hline
\end{tabular}

\subsection{Sensory evaluation of the waxy rice starch gel with added Chew-Kuk}

Sensory evaluation of waxy rice starch gel with added Chew-Kuk at Chew-Kuk : waxy rice starch ratios of $3: 100,5: 100,10: 100,15: 100$, and 20:100 were evaluated. The waxy rice starch gel without Chew-Kuk was used as a control sample. The sensory evaluation results are presented in Table 2 .

Table 2. Sensory evaluations of the waxy rice starch gel with added Chew-Kuk.

\begin{tabular}{|c|c|c|c|c|c|}
\hline \multirow{2}{*}{$\begin{array}{l}\text { Chew-Kuk: } \\
\text { Waxy Rice } \\
\text { Starch Ratios }\end{array}$} & \multicolumn{5}{|c|}{ Sensory Evaluation Scores* } \\
\hline & Color & Odor & Texture & Appearance & Overall \\
\hline control & $2.70^{\mathrm{ns}} \pm 0.57$ & $2.30^{\mathrm{d}} \pm 0.47$ & $2.95^{\mathrm{c}} \pm 0.51$ & $3.80^{\mathrm{ns}} \pm 0.61$ & $3.05^{\mathrm{b}} \pm 0.39$ \\
\hline $3: 100$ & $2.75^{\mathrm{ns}} \pm 0.55$ & $2.40^{\mathrm{d}} \pm 0.50$ & $3.00^{\mathrm{c}} \pm 0.46$ & $3.70^{\mathrm{ns}} \pm 0.66$ & $3.15^{\mathrm{b}} \pm 0.49$ \\
\hline $5: 100$ & $2.80^{\mathrm{ns}} \pm 0.52$ & $2.50^{\mathrm{cd}} \pm 0.51$ & $3.05^{\mathrm{c}} \pm 0.51$ & $3.75^{\mathrm{ns}} \pm 0.64$ & $3.20^{\mathrm{b}} \pm 0.52$ \\
\hline $10: 100$ & $2.85^{\mathrm{ns}} \pm 0.49$ & $2.80^{\mathrm{bc}} \pm 0.62$ & $3.25^{\mathrm{bc}} \pm 0.72$ & $3.75^{\mathrm{ns}} \pm 0.72$ & $3.40^{\mathrm{ab}} \pm 0.60$ \\
\hline $15: 100$ & $2.70^{\mathrm{ns}} \pm 0.47$ & $2.95^{\mathrm{ab}_{ \pm}} 0.60$ & $3.55^{\mathrm{ab}} \pm 0.69$ & $3.45^{\mathrm{ns}} \pm 0.83$ & $3.45^{\mathrm{ab}} \pm 0.69$ \\
\hline $20: 100$ & $2.55^{\mathrm{ns}} \pm 0.60$ & $3.25^{\mathrm{a}} \pm 0.85$ & $3.80^{\mathrm{a}} \pm 0.77$ & $3.30^{\mathrm{ns}} \pm 0.80$ & $3.75^{\mathrm{a}} \pm 0.79$ \\
\hline
\end{tabular}

*Values followed by the same letter are not significantly different $(P \geq 0.05)$. 
As in Table 2, the results show that the liking scores of color and appearance of control sample and the waxy rice starch gel with added Chew-Kuk at various Chew-Kuk : waxy rice starch ratios were not significantly different. The results indicated that Chew-Kuk did not affect liking of consumer regarding color and appearance of waxy rice starch gel. For the liking scores of odor, texture, and overall liking of waxy rice starch gel with added ChewKuk, the results suggested that consumers tended to like waxy rice starch gel with ChewKuk more than the waxy rice starch gel alone (control sample). The liking scores for odor, texture, and overall liking of the waxy rice starch gel with added Chew-Kuk increased with increasing of Chew-Kuk : waxy rice starch ratios.

\subsection{Color of the waxy rice starch gel with added Chew-Kuk}

Table. 3 shows $\mathrm{L}^{*}, \mathrm{a}^{*}$, and $\mathrm{b}^{*}$ values of the waxy rice starch gel with Chew-Kuk at various Chew-Kuk : waxy rice starch ratios and waxy rice starch gel without Chew-Kuk (control sample). The results show that the waxy rice starch gel with added Chew-Kuk was yellowish green. The $\mathrm{L}^{*}$ and $\mathrm{a}^{*}$ values decreased with an increase of Chew-Kuk : waxy rice starch ratios. These results implied that the waxy rice starch gel will have a darker green color when adding Chew-Kuk to its contents. However, b* value was not depending on Chew-Kuk.

Table 3. Color of the waxy rice starch gel with added Chew-Kuk.

\begin{tabular}{|c|c|c|c|}
\hline \multirow{2}{*}{$\begin{array}{c}\text { Chew-Kuk : Waxy Rice } \\
\text { Starch Ratios }\end{array}$} & \multicolumn{3}{|c|}{ Color* } \\
\cline { 2 - 4 } & $\mathrm{L}^{*}$ & $\mathrm{a}^{*}$ & $\mathrm{~b}^{*}$ \\
\hline control & $68.66^{\mathrm{a}} \pm 0.37$ & $-0.26^{\mathrm{a}} \pm 0.09$ & $6.36^{\mathrm{b}} \pm 0.12$ \\
\hline $3: 100$ & $61.54^{\mathrm{b}} \pm 1.37$ & $-0.42^{\mathrm{a}} \pm 0.09$ & $10.41^{\mathrm{a}} \pm 0.64$ \\
\hline $5: 100$ & $61.01^{\mathrm{b}} \pm 1.63$ & $-0.44^{\mathrm{a}} \pm 0.36$ & $10.73^{\mathrm{a}} \pm 0.05$ \\
\hline $10: 100$ & $53.85^{\mathrm{c}} \pm 1.58$ & $-0.68^{\mathrm{b}} \pm 0.16$ & $11.27^{\mathrm{a}} \pm 1.23$ \\
\hline $15: 100$ & $49.45^{\mathrm{d}} \pm 4.41$ & $-0.85^{\mathrm{c}} \pm 0.20$ & $11.04^{\mathrm{a}} \pm 0.14$ \\
\hline $20: 100$ & $47.80^{\mathrm{d}} \pm 0.70$ & $-1.63^{\mathrm{d}} \pm 0.07$ & $11.34^{\mathrm{a}} \pm 0.91$ \\
\hline
\end{tabular}

*Values followed by the same letter are not significantly different $(P \geq 0.05)$.

\subsection{Texture profile of the waxy rice starch gel with added Chew-Kuk}

Hardness (height of the first peak), cohesiveness (ratio of the area under the second peak to the area under the first peak), springiness (ratio between the recovered height after the first compression and the original gel height), gumminess (hardness multiplied by cohesiveness) and chewiness (hardness multiplied by springiness and cohesiveness) are important parameters which can demonstrate textural profiles of the material. The texture profile results of the waxy rice starch gel with added Chew-Kuk at various Chew-Kuk : waxy rice starch ratios and the waxy rice starch gel without Chew-Kuk (control sample) results are presented in Figure 1.

For hardness results as in Figure 1(a), hardness value decreased when Chew-Kuk : waxy rice starch ratios increased. The waxy rice starch gel was less stiff when adding Chew-Kuk, thus, the result indicated that its rigidity may be characterized by the content of Chew-kuk. This may due to swelling and solubility of starch after adding Chew-kuk.

For cohesiveness results as in Figure 1(b), the results show that the cohesiveness values were less when Chew-Kuk was added at Chew-Kuk : waxy rice starch ratio of 3:100. When 
Chew-Kuk at higher quantities were added, the cohesiveness values tended to be higher. However, at the Chew-Kuk : waxy rice starch ratio of 15:100, the cohesiveness values decreased. In case of springiness in Figure 1(c), springiness of the waxy rice starch gel with added Chew-Kuk slightly increased when Chew-Kuk : waxy rice starch ratios were increased. High cohesiveness and springiness could be a result of Chew-kuk's swelling and solubility during starch gelatinization [8].

In Figure 1(d) and Figure 1(e), gumminess and chewiness of the waxy rice starch gel with added Chew-Kuk slightly decreased when Chew-Kuk : waxy rice starch ratios were increased. Gumminess and chewiness values are the products of hardness. Therefore, the gumminess and chewiness values also have tendency similar to the hardness values. The gumminess and chewiness were decreased when hardness of waxy rice starch gel with ChewKuk was decreased. When compared these results with the sensory evaluation results in item 3.1 , the results indicated that consumers liked the waxy rice starch gel that was soft and elastic, which were the properties obtained after adding Chew-Kuk.

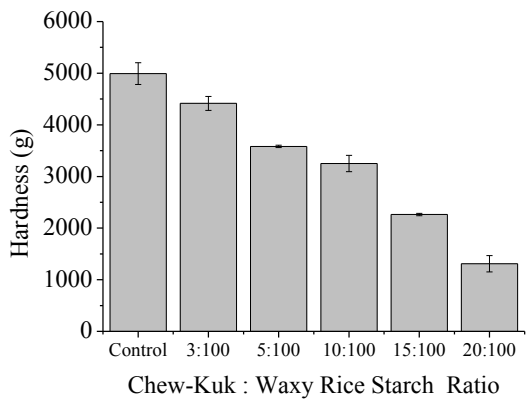

(a)

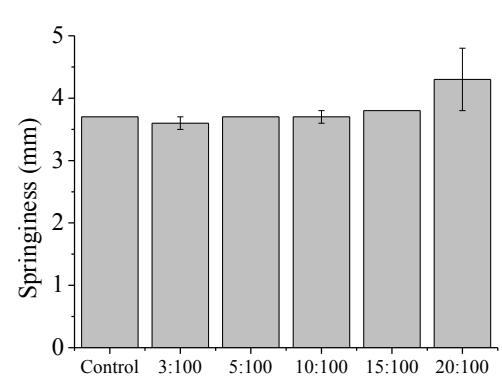

Chew-Kuk : Waxy Rice Starch Ratio

(c)

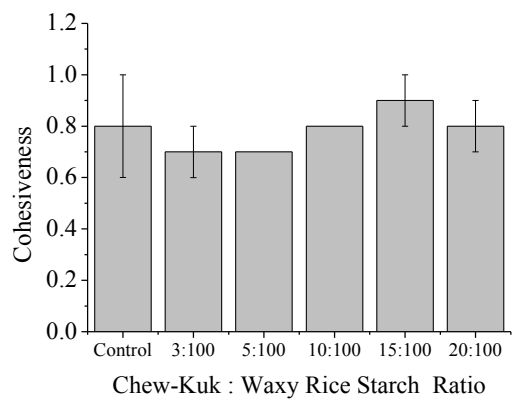

(b)

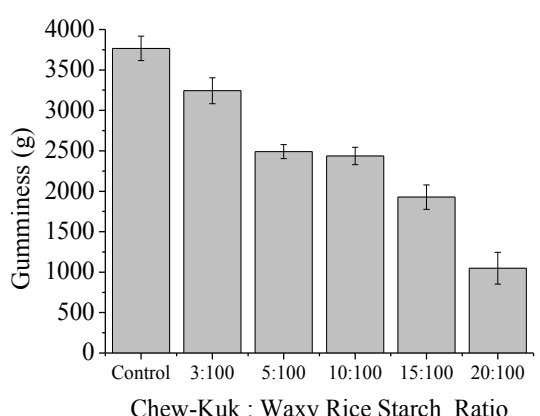

(d)

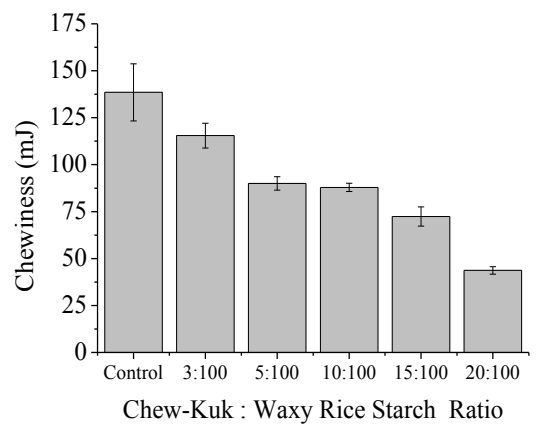

(e)

Fig. 1. Textural properties of the waxy rice starch gel with added Chew-Kuk. 


\section{Conclusion}

Chew-Kuk has significant effects on the physical properties of waxy rice starch gel. Consumers can sense the change of color, ordor, and texture of the waxy rice starch gel when Chew-Kuk was added. They liked the waxy rice starch gel with added Chew-Kuk more than the original one. Chew-Kuk helps the waxy rice starch gel to be decreases hardness, gumminess and chewiness. In addition, Chew-Kuk also gives a pleasant aroma. From this research, waxy rice starch gel was prepared with Chew-kuk for which $100 \mathrm{~g}$ of dried ChewKuk was boiled in water for $30 \mathrm{~min}$ at $100^{\circ} \mathrm{C}$. Then, boiled Chew-Kuk was mixed with waxy rice starch at the Chew-Kuk : waxy rice starch ratios of 20:100 in order to prepare starch dough. Consequently, the dough was steamed for $30 \mathrm{~min}$ at $100^{\circ} \mathrm{C}$.

This research was funded by King Mongkut's University of Technology North Bangkok. Contract no. KMUTNB-62-DRIVE-23.

\section{References}

1. An editorial committee of Chinese academy of sciences of flora reipublicae popularis sinicae, Flora reipublicae popularis sinicae (Scientific press, Beijing, 1979)

2. G. Rojas, J. Lévaro, J. Tortoriello, V. Navarro, J. Ethnopharmacol. 74(1), 97-101 (2001)

3. J.R. Villagómez-Ibarra, M. Sánchez, O. Espejo, A. Zúñiga-Estrada, J.M. TorresValencia, P. Joseph-Nathan, Fitoterapia 72(6), 692-694 (2001)

4. W.C. Zeng, W.C. Zhang, W.H. Zhang, Q. He, B. Shi, Food Chem. Toxicol. 58, 311-317 (2001)

5. P. Sahakitpichan, W. Disadee, S. Ruchirawat, T. Kanchanapoom, Chem. Pharm. Bull. 59(9), 1160-1162 (2011)

6. A. Ampaichit, Development of ready mixed Kha-Nom Thien flour with Chew-Kuk (M Sci Thesis, Silapakorn University, 2009)

7. AOAC, Official methods of analysis (Washington DC, Association of Official Analytical Chemistry, 1990)

8. N. Seetapan, N. Limparyoon, C. Gamonpilas, P. Methacanon, A. Fuongfuchat, J. Food Eng. 151, 51-59 (2015) 